\title{
Calcitriol But No Other Metabolite of Vitamin D Is Essential for Normal Bone Growth and Development in the Rat
}

\author{
A. M. Parfitt and C. H. E. Mathews \\ Bone and Mineral Research Laboratory, Department of \\ Medicine, Henry Ford Hospital, Detroit, Michigan 48202
}

R. Brommage, K. Jamagin, and H. F. Deluca

Department of Biochemistry, College of Agriculture and Life

Sciences, University of Wisconsin, Madison, Wisconsin, 53706

bstract. To determine the relative importance of different metabolites of vitamin $\mathrm{D}$ in bone growth and development, weanling male rat pups suckled by vitamin D-deficient mothers were given either calcitriol $(1,25-$ dihydroxycholecalciferol) by continuous subcutaneous infusion, oral calcidiol (25-hydroxycholecalciferol), or oral 24,24-difluoro-25-hydroxycholecalciferol, a synthetic compound that can undergo 1-hydroxylation but not 24hydroxylation, as their sole source of vitamin D for $\mathbf{4 0}$ d. Pups raised in the same manner, but given no vitamin $\mathrm{D}$, served as controls. The three metabolites compared were given in doses that restored normal plasma calcium levels and normal increments in body weight. After in vivo double tetracycline labeling, bone histomorphometry by standard methods was performed on one femur and one tail vertebra. There were no significant differences between the three metabolite-treated groups in length, periosteal or endosteal diameter, cortical cross-sectional area, cortical porosity, osteoid thickness and volume, appositional rate and bone formation rate in the femur, or in qualitative and quantitative indices of endochondral ossification in the tail vertebra. All three groups differed markedly from the untreated controls with respect to all measurements. Collectively, the data indicate that neither calcidiol nor any 24-hydroxylated metabolite of calcidiol is needed in the rat (other than as a precursor) for longitudinal or transverse bone growth, for normal endochondral ossification, or for normal periosteal and endosteal formation, mineralization, and resorption of bone.

Received for publication 11 March 1983 and in revised form 2 August 1983.

J. Clin. Invest.

(c) The American Society for Clinical Investigation, Inc.

0021-9738/84/02/0576/11 $\$ 1.00$

Volume 73, February 1984. 576-586
Calcitriol was fully active with respect to each of the indices listed when given in a manner resembling its continuous endogenous production by the kidney, suggesting that previous reports of incomplete skeletal response to calcitriol result from its rapid clearance and infrequent oral administration. We demonstrated that calcitriol is the only metabolite that is both necessary and sufficient for normal bone growth and development in the rat, but our data do not indicate the extent to which its beneficial skeletal effects were mediated by direct action on bone, either of calcitriol itself or of some metabolite thereof, or by restoration of normal plasma levels of calcium and phosphate.

\section{Introduction}

The main physiologic actions of vitamin $D(1,2)$ are to increase the intestinal absorption of calcium and phosphate and to promote the deposition of these minerals in epiphyseal growth plate cartilage and newly formed bone. In addition, vitamin D works with parathyroid hormone in regulating the release of calcium from bone in the control of plasma calcium levels. As a result, deficiency of vitamin D in a growing animal causes rickets, hypocalcemia, and secondary hyperparathyroidism. The naturally occurring form of vitamin $D$ is cholecalciferol, or vitamin $D_{3}$. This compound is converted in the liver to 25-hydroxycholecalciferol (calcidiol), which is then converted in the kidney either to 1,25-dihydroxycholecalciferol (calcitriol; $\left.1,25[\mathrm{OH}]_{2} \mathrm{D}_{3}\right)^{1}$ or 24,25 -dihydroxy cholecalciferol $\left(24,25[\mathrm{OH}]_{2} \mathrm{D}_{3}\right)$. Calcitriol is further metabolized to 1,24,25-trihydroxycholecalciferol $\left(1,24,25[\mathrm{OH}]_{3} \mathrm{D}_{3}\right)$, a compound that may carry out some of the biologic functions of calcitriol but more likely is the first step in a degradation pathway $(1,2)$.

1. Abbreviations used in this paper: $24,24 \mathrm{~F}_{2} 25 \mathrm{OHD}_{3}, 24,24$-difluoro25-hydroxyvitamin $D_{3} ; 1,25(O H)_{2} D_{3}, 1,25$-dihydroxyvitamin $D_{3}$; $24,25(\mathrm{OH})_{2} \mathrm{D}_{3}, 24-25$-dihydroxyvitamin $\mathrm{D}_{3} ; 1,24,25(\mathrm{OH})_{3} \mathrm{D}_{3}, 1,24,25$ trihydroxyvitamin $\mathrm{D}_{3}$. 
The question of which of these and possibly other metabolites are responsible for the physiologic actions of vitamin $\mathrm{D}$ has been the subject of much research. It is now generally agreed that calcitriol is mainly and perhaps entirely responsible for promoting intestinal calcium and phosphate absorption and calcium release from bone, but some investigators believe that an additional metabolite, either calcidiol (3-6) or $24,25(\mathrm{OH})_{2} \mathrm{D}_{3}$ (7-11) is necessary for normal growth and mineralization of bone. A partly related issue concerns whether mineralization is controlled entirely by the plasma levels of calcium and phosphate or whether some metabolite of vitamin $\mathrm{D}$ such as calcidiol or $24,25(\mathrm{OH})_{2} \mathrm{D}_{3}$ has an additional, more direct effect on bone to promote mineralization $(1,2)$. It must be emphasized that whether $24,25(\mathrm{OH})_{2} \mathrm{D}_{3}$ has a physiologic function is a separate question from the pharmacologic effects and possible therapeutic uses of this compound $(12,13)$.

In several studies that claim an incomplete skeletal response to calcitriol (11), no account has been taken of its short biological lifetime (14). Calcidiol might appear more effective because the continuous supply of calcitriol (from renal 1-hydroxylation of its precursor) maintained higher or more constant blood levels than could be achieved by intermittent oral administration. Accordingly, in this study we have given calcitriol to vitamin D-deficient rats by continuous infusion as the only metabolite, in a dose that restores normal levels of plasma calcium and normal body weights. When given in this way, calcitriol has effects that are indistinguishable from those of calcidiol, and promotes histologically normal growth, formation, mineralization, and resorption of both bone and epiphyseal growth plate cartilage, as judged by quantitative histomorphometry after in vivo double tetracycline labeling. Furthermore, we demonstrate that 24,24-difluoro-25-hydroxyvitamin $\mathrm{D}_{3}$ $\left(24,24 \mathrm{~F}_{2} 25 \mathrm{OHD}_{3}\right)$, a synthetic vitamin $\mathrm{D}_{3}$ analogue that can undergo 1-hydroxylation but not 24-hydroxylation (15-17), is fully active with respect to all the histologic indices examined, extending previous work on this subject $(18,19)$. Together these results establish that calcitriol is both necessary and sufficient for normal bone development in the rat, but that neither calcidiol nor $24,25(\mathrm{OH})_{2} \mathrm{D}_{3}$ has any physiologically important skeletal function in this species.

\section{Methods}

Low vitamin D, sperm positive, female Holtzman rats (Holtzman Co., Madison, WI) were placed on a vitamin D-deficient semipurified diet containing $0.47 \%$ calcium and $0.30 \%$ phosphorus $(20)$. When vitamin $\mathrm{D}$ was added, this diet sustained completely normal growth and development and normal plasma levels of calcium and phosphate in this strain of rat. Male pups were marked $4 \mathrm{~d}$ after birth by clipping the right ear. After weaning at $23 \mathrm{~d}$, the pups were separated by sex. Evidence that pups raised in this manner are vitamin $D$ deficient by weaning is given elsewhere (21). 47 male pups were divided at random into four groups and placed on the diet previously specified; feeding was ad lib. for all groups. Group 1 received $50 \mathrm{pmol} / \mathrm{d}$ of calcitriol dissolved in propylene glycol by continuous subcutaneous infusion delivered by an Alzet osmotic minipump, model 2002 (Alza Corp., Palo Alto, CA).
Group 2 received $100 \mathrm{pmol} / \mathrm{d}$ of $24,24 \mathrm{~F}_{2} 25 \mathrm{OHD}_{3}$ given orally three times weekly in $0.1 \mathrm{ml}$ of cotton seed-soybean oil (Wesson oil). Group 3 received $100 \mathrm{pmol} / \mathrm{d}$ of calcidiol given in the same manner. Calcidiol is the precursor of every known biologically active metabolite and can accomplish every known function of vitamin $\mathrm{D}(1,2)$, so that group 3 served as a positive control group for the other metabolites. Group 4 received only the same dose of Wesson oil and so served as a negative control group for the other metabolites. The pups were housed in individual, hanging wire cages, in rooms kept on a 12-h day/night cycle, using incandescent lighting and therefore free from ultraviolet light. For groups 1,2 , and 4, no other rats in the same room received any form of vitamin D other than those used in this experiment. Consequently, all extraneous sources of vitamin $\mathrm{D}$, both endogenous and exogenous, were eliminated. Seven additional male animals born to vitamin D-deficient mothers (group 5) were killed at weaning and used for indirect estimation of longitudinal and transverse growth and net endosteal resorption in groups $1-4$.

The osmotic minipumps were implanted according to the manufacturer's directions except that the back of the animal was washed with an antiseptic solution instead of shaved. Also, the pump was coated with Panalog ointment (Squibb and Sons, Inc., Princeton, NJ) before implantation to minimize infection. The pumps were reimplanted every $2 \mathrm{wk}$. In the alternate weeks all rats in groups 1-4 only were weighed and $\sim 50 \mu \mathrm{l}$ of blood was collected from the tail vein of five rats in each group for chemical analysis. On days 22 and 23 postweaning, all rats except group 5 were given $2 \mathrm{mg}$ of oxytetracycline, and on days 36 and 37 postweaning $3 \mathrm{mg}$ of tetracycline. In normally growing rats these doses were equivalent to $12-13 \mathrm{mg} / \mathrm{kg}$ body weight on each day of the 2-d labeling periods. Rats in group 5 received no tetracycline. Two animals died during the experiment, but all other rats except group 5 were killed at $40 \mathrm{~d}$ after weaning, or $63 \mathrm{~d}$ after birth.

At death, both femurs were removed from each animal and cleaned of adherent soft tissue. One of each pair was used for determination of organic and ash weights as described and reported previously (22). The other was placed in $70 \%$ ethanol and used to obtain the morphometric data reported here. In addition, from all animals in groups 1-4 the most cephalad tail vertebra was removed, cleaned, and placed in $70 \%$ ethanol. The intact femurs were radiographed for determination of gross structure. The length of each bone was measured both directly and on the film; in some cases a correction was made for missing condyles. Several slabs of 1-mm thickness were sawn from the diaphysis close to the midpoint of each femur, and were wet-sanded to $\sim 100 \mu \mathrm{m}$. One section was dehydrated and mounted unstained, and the others were stained with Villanueva osteochrome (23) for 3-4 h before dehydration and mounting. The vertebrae were stained with osteochrome for $48 \mathrm{~h}$, dehydrated, and embedded in polymethyl methacrylate (24). Longitudinal sections were cut with a Jung-K microtome; $5 \mu \mathrm{m}$-sections were stained with toluidine blue (25) and $10-\mu \mathrm{m}$ sections were examined without further staining.

On the transverse femoral sections (at least two per animal) we measured periosteal and endosteal perimeter lengths, the mean width of osteoid along periosteal and endosteal surfaces and, when present, in cortical channels, the total area enclosed within the periosteum and the total marrow area enclosed by the endosteum; the difference between these latter measurements represented total cortical area. The lengths of tetracycline labels and areas between the labels were measured using ultraviolet illumination to excite fluorescence. These length, width, and area measurements were performed with a Zeiss MOP-3 digitizing system (Carl Zeiss, Inc., New York) (26). The relative proportions of mineralized bone, unmineralized osteoid, and vascular channel in each cortical crosssection were measured by counting point hits using a Zeiss integration 
plate II eyepiece graticule with 100 points (27). In cases where some surface osteoid had been lost during specimen preparation, osteoid area was determined as the product of mean osteoid width and tetracycline label length. On the vertebral sections we measured the widths of proliferative cartilage, hypertrophic cartilage, and total epiphyseal growth plate, and made qualitative observations of the integrity of endochondral ossification (19). Also, the relative proportions of mineralized bone and unmineralized osteoid were measured in newly formed trabecular bone in the metaphyses. The relationships between variables were examined using product-moment correlation and regression analysis, and the significance of differences between means was determined by an unpaired $t$ test or by one-way analysis of variance as appropriate (28). The measurements were carried out without knowledge of the experimental group to which the specimen belonged, although the identity of all sections from vitamin D-deficient animals was obvious to simple inspection.

\section{Results}

Representative sections of the femoral diaphysis from groups 1-4 are shown in Fig. 1. There were obvious qualitative dif-
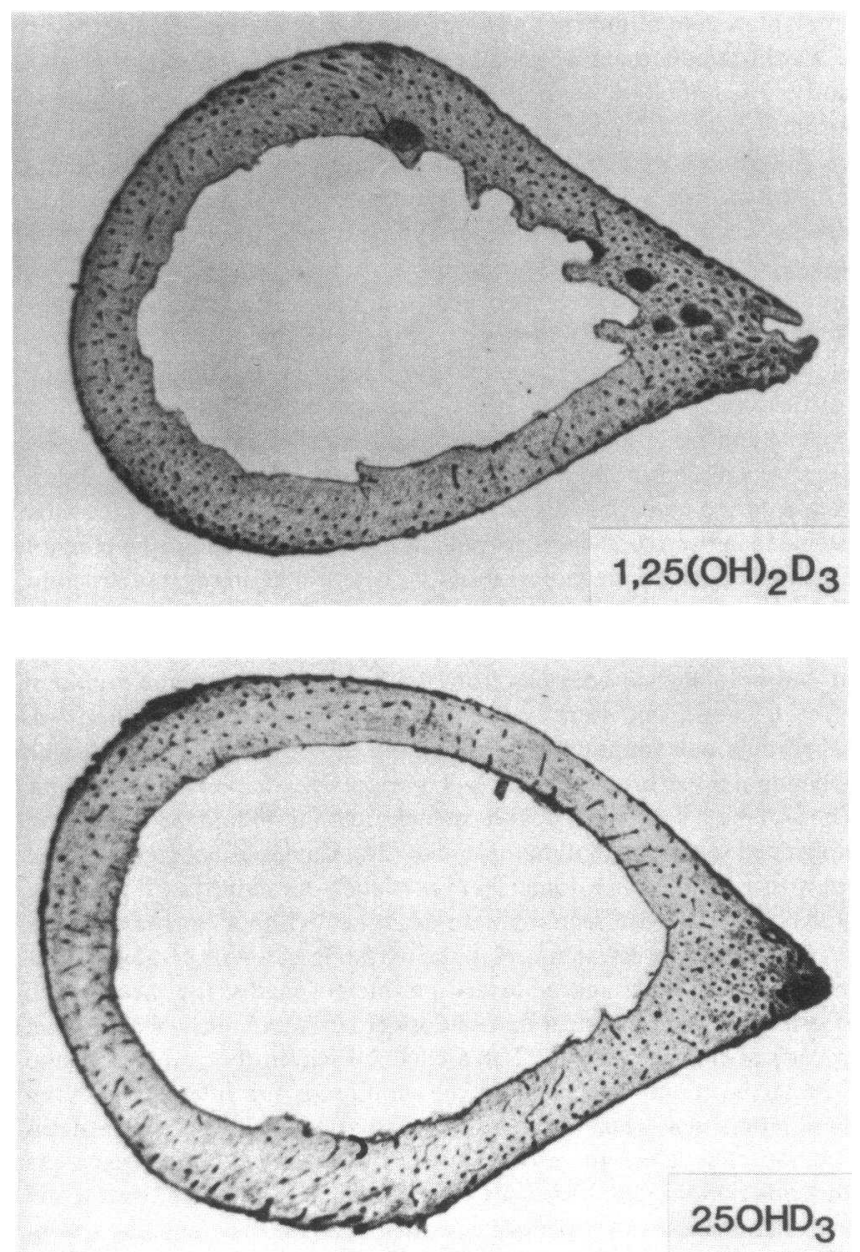

ferences between the vitamin D-repleted rats (groups 1-3) and the vitamin D-deficient rats (group 4), but none between the different vitamin D-repleted groups. As well as being smaller, the bones of the vitamin D-deficient rats were structurally disorganized and much more porous, with large vascular channels.

The mean lengths and cross-sectional measurements of the femurs in each group are given in Table I. There was no significant difference between groups 1,2 , and 3 in any measurement, but each of these groups individually differed significantly from group 4 in all measurements except cortical area. For indirectly calculated cortical thickness, the differences were significant for the pooled data but not for the individual groups, except with a one-tailed test. The data indicate that all three compounds studied were equally effective in correcting the bone structural effects of vitamin $\mathrm{D}$ deficiency. Comparing the vitamin D-deficient animals with the pooled vitamin D-repleted animals, there was a substantial reduction in both longitudinal and transverse bone growth. Marrow cavity expansion due to net endosteal
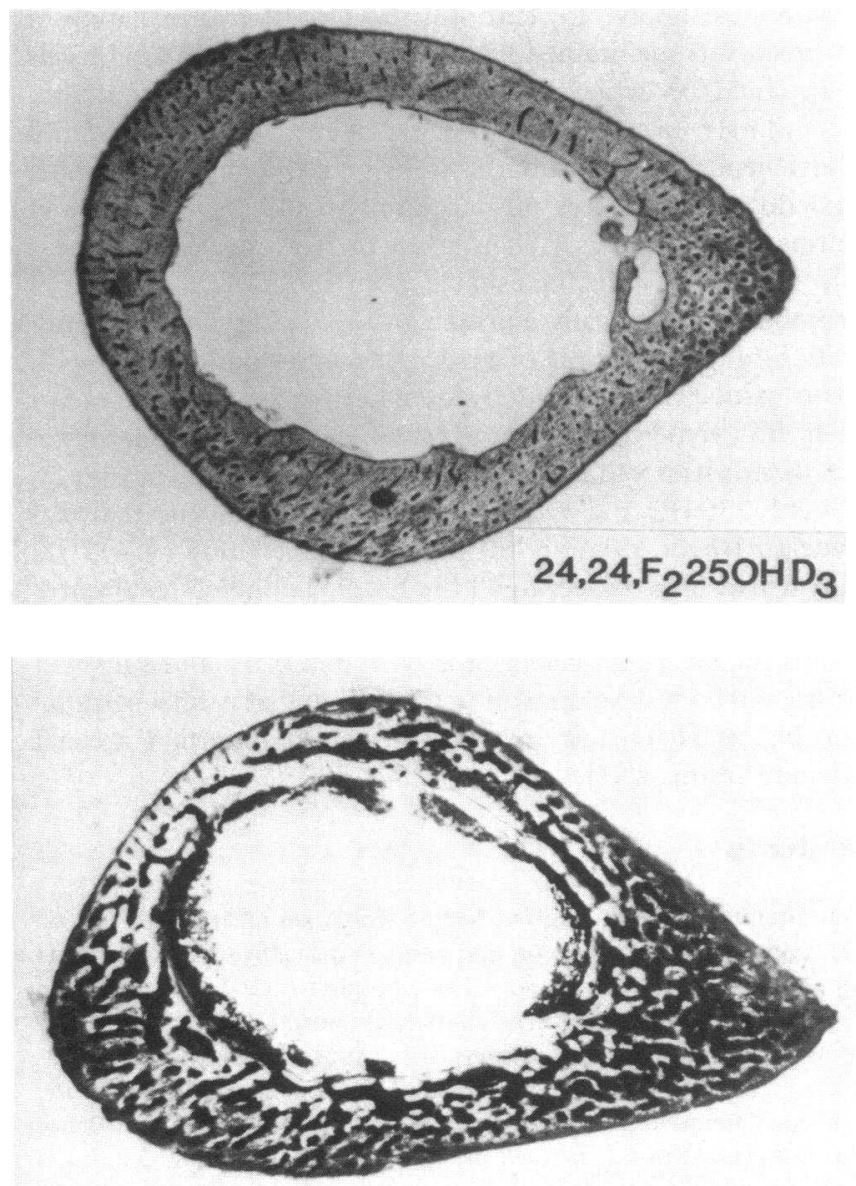

NO VITAMIN D

Figure 1. Representative cross-sections of femoral diaphysis. 
Table I. Measurements of Femoral Bone Structure and Growth in Different Experimental Groups

\begin{tabular}{|c|c|c|c|c|c|c|}
\hline $\begin{array}{l}\text { Group ( } n \text { ) } \\
\text { Treatment }\end{array}$ & $\begin{array}{l}1(10) \\
\text { Calcitriol }\end{array}$ & $\begin{array}{l}2(11) \\
24,24 F_{2}\end{array}$ & $\begin{array}{l}3(11) \\
\text { Calcidiol }\end{array}$ & $\begin{array}{l}\text { Pooled (32) } \\
\text { D-+(63) }\end{array}$ & $\begin{array}{l}4(13) \\
D--(63)\end{array}$ & $\begin{array}{l}5(5) \\
D-(23)\end{array}$ \\
\hline Length $(\mathrm{mm})$ & $31.9 \pm 0.9 \ddagger$ & $31.7 \pm 1.7 \ddagger$ & $31.0 \pm 1.3 \ddagger$ & $31.5 \pm 1.4 \ddagger$ & $21.2 \pm 2.3$ & $16.0 \pm 0.1$ \\
\hline Total area $\left(\mathrm{mm}^{2}\right)$ & $10.78 \pm 2.47 \ddagger$ & $9.88 \pm 1.23 \ddagger$ & $9.39 \pm 1.14^{*}$ & $9.99 \pm 1.74 \ddagger$ & $7.60 \pm 1.46$ & $2.82 \pm 0.47$ \\
\hline Marrow area $\left(\mathrm{mm}^{2}\right)$ & $6.02 \pm 2.64 \ddagger$ & $5.10 \pm 1.15 \ddagger$ & $4.80 \pm 0.98 \ddagger$ & $5.29 \pm 1.74 \ddagger$ & $3.08 \pm 0.81$ & $1.58 \pm 0.31$ \\
\hline Cortical area $\left(\mathrm{mm}^{2}\right)$ & $4.76 \pm 0.52$ & $4.82 \pm 0.86$ & $4.59 \pm 0.89$ & $4.72 \pm 0.76$ & $4.52 \pm 1.01$ & $1.24 \pm 0.22$ \\
\hline Cortical area/total ratio & $0.46 \pm 0.10 \ddagger$ & $0.49 \pm 0.08 \ddagger$ & $0.49 \pm 0.08 \ddagger$ & $0.48 \pm 0.08 \ddagger$ & $0.60 \pm 0.06$ & $0.44 \pm 0.04$ \\
\hline Periosteal perimeter $(\mathrm{mm})$ & $12.46 \pm 1.18 \ddagger$ & $12.05 \pm 0.95 \ddagger$ & $11.80 \pm 1.00^{*}$ & $12.09 \pm 1.04 \ddagger$ & $10.51 \pm 0.95$ & $6.08 \pm 0.44$ \\
\hline Endosteal perimeter $(\mathrm{mm})$ & $9.93 \pm 1.48$ & $9.92 \pm 2.23$ & $8.98 \pm 1.07$ & $9.60 \pm 1.68$ & $6.40 \pm 0.86$ & $4.56 \pm 0.41$ \\
\hline \multicolumn{7}{|l|}{ Calculated values } \\
\hline Periosteal radius $(\mathrm{mm})$ & $1.84 \pm 0.20 \ddagger$ & $1.77 \pm 0.11 \ddagger$ & $1.73 \pm 0.11 \ddagger$ & $1.78 \pm 0.15 \ddagger$ & $1.55 \pm 0.15$ & $0.95 \pm 0.08$ \\
\hline Endosteal radius $(\mathrm{mm})$ & $1.36 \pm 0.28 \ddagger$ & $1.27 \pm 0.14 \ddagger$ & $1.23 \pm 0.13 \ddagger$ & $1.29 \pm 0.15 \ddagger$ & $0.98 \pm 0.13$ & $0.71 \pm 0.07$ \\
\hline Cortical thickness $(\mathrm{mm})$ & $0.48 \pm 0.10$ & $0.50 \pm 0.11$ & $0.50 \pm 0.10$ & $0.49 \pm 0.10$ & $0.57 \pm 0.09$ & $0.24 \pm 0.03$ \\
\hline Length/width ratio & $8.81 \pm 0.89 \ddagger$ & $8.97 \pm 0.65 \ddagger$ & $9.04 \pm 0.62 \ddagger$ & $9.95 \pm 0.69 \ddagger$ & $6.80 \pm 0.84$ & $8.51 \pm 0.65$ \\
\hline
\end{tabular}

Numbers in parentheses on line 2 are age at death in days. The data are given as mean \pm SD. $D-+$, pooled data for groups $1-3$, representing rats that were vitamin D-deficient from birth to weaning, and vitamin D-repleted from weaning to death; D--, vitamin D-deficient from birth to weaning and from weaning to death; D-, vitamin D-deficient from birth to death at weaning. Total area is area enclosed by periosteal perimeter, marrow area is area enclosed by endosteal perimeter, and cortical area is difference between total and marrow area. Periosteal and endosteal radii are calculated assuming a circular cross-section; the difference between these calculated values is an estimate of mean cortical thickness. Width is equal to doubled periosteal radius. For groups 1-3 and pooled D-+, significance levels refer to comparison with group 4. One-way analysis of variance showed no significant differences between groups 1,2 , and 3 . $^{*}=P<0.01 . \quad \ddagger=P<0.001$.

resorption was retarded to an even greater extent, so that cortical thickness and cortical area as a fraction of total area were both increased, but absolute cortical area (including porosity and osteoid) was unchanged. The length/width ratio (an index of bone shape) was significantly reduced. Comparing both the vitamin D-deficient rats and the pooled vitamin D-repleted rats to vitamin D-deficient rats killed at weaning (group 5), differences in rates of longitudinal and transverse growth can be estimated (Table II). The femurs grew in length almost three times as fast during vitamin $\mathrm{D}$ repletion as during continued vitamin $\mathrm{D}$ depletion, but grew in width only $40 \%$ faster; the rate of endosteal expansion was more than doubled. These differences were similar whatever form of vitamin D was given, and are summarized diagrammatically in Fig. 2.

The measurements of osteoid width and volume and of intracortical porosity are shown in Table III. As before, there were no significant differences in any measurement between groups 1,2 , and 3, but each of these groups differed significantly in all measurements from group 4. In the treated rats, relative osteoid volume was only $\sim 2 \%$ in the femoral diaphysis and $\sim 8 \%$ in the vertebral metaphysis, osteoid seam width was $<7$ $\mu \mathrm{m}$ at both sites, and cortical porosity was $\sim 3 \%$. In the vitamin D-deficient rats, osteoid volume was increased about fivefold in the vertebrae and more than 10-fold in the femur, and osteoid width was increased about two- to threefold. Vascular canal volume and resultant porosity were increased $\sim 10$-fold, indicating incomplete closure of the primary osteons formed during periosteal apposition and transverse bone growth. From the relative reductions in femoral length, cross-sectional area, and proportion of mineralized bone in the vitamin D-deficient rats, the estimated ash content would be reduced to 33\% compared with the vitamin D-repleted rats, which agrees well with the measured reduction to $34 \%$ (22).

Table II. Effects of Vitamin D Depletion and Repletion on Longitudinal and Transverse Bone Growth

\begin{tabular}{lclc}
\hline $\begin{array}{l}\text { Group }(n) \\
\text { Treatment }\end{array}$ & $\begin{array}{l}4(13) \\
\mathrm{D}--\end{array}$ & $\begin{array}{l}\text { Pooled (32) } \\
\mathrm{D}-+\end{array}$ & Difference \\
\hline $\begin{array}{l}\text { Longitudinal growth } \\
(\mu \mathrm{m} / \mathrm{d})\end{array}$ & 130 & 387 & $257 \quad(+198 \%)$ \\
$\begin{array}{l}\text { Net periosteal expansion } \\
(\mu \mathrm{m} / \mathrm{d})\end{array}$ & 15.0 & 20.8 & $5.8(+39 \%)$ \\
$\begin{array}{l}\text { Net endosteal expansion } \\
(\mu \mathrm{m} / \mathrm{d})\end{array}$ & 6.8 & 14.5 & $7.7(+113 \%)$ \\
\hline
\end{tabular}

The transverse rates are calculated from the differences between the mean calculated radii at death and the mean calculated radii in the vitamin D-deficient weanling rats, divided by the age difference of $\mathbf{4 0}$ d. The calculated rates of increase in diameter will be twice as great. The percentage values are the relative increases in rates produced by vitamin D repletion after weaning. Individual growth rates cannot be determined, so that standard deviations are not given; the significances of the differences are the same as for the primary measurements in Table I. 


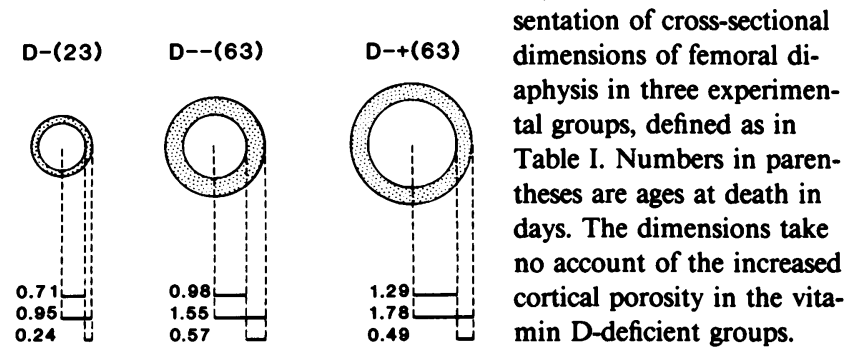

Appositional rates and bone formation rates based on tetracycline labeling are given in Table IV. As in the tibia (29), bone formation in the femur in young rats normally occurs over the entire periosteal surface and over a segment of the endosteal surface, the remainder of which is undergoing resorption. Consequently, there were two pairs of tetracycline labels in all the vitamin D-repleted rats in groups 1, 2, and 3 (Fig. 3). The endosteal labels were intact, indicating that only a trivial fraction of the bone formed during the experimental period had been resorbed. There were no significant differences between groups 1,2 , and 3 in the mean appositional rates or in the total extent of new bone deposited between the tetracycline labels, combining bone formed on both periosteal and endosteal surfaces, whether expressed as an absolute area or as a percent of cortical area, or in the corresponding bone formation rates. In the vitamin D-deficient rats, the tetracycline uptake was scanty, irregular, and diffuse and it was not possible to measure an area enclosed by the labels in any animal (Fig. 3).

The epiphyseal growth plate cartilage measurements in tail vertebra are given in Table V. Proliferative cartilage width was slightly greater in group 3 than in groups 1 and 2, and hypertrophic cartilage width was slightly greater in group 2 than in groups 1 and 3, but total epiphyseal cartilage width did not differ significantly between the three groups. Each of groups 1, 2 , and 3 individually differed significantly from group 4 in all three measurements, and these differences were of much greater magnitude than the differences within groups 1,2 , and 3. Compared with the pooled vitamin D-repleted rats, the vitamin D-deficient rats showed a $41 \%$ increase in proliferative cartilage width, a $249 \%$ increase in hypertrophic cartilage width, and a $91 \%$ increase in total width. Because growth in length was reduced, the increase in proliferative cartilage width resulted from an even greater reduction in the rate of cartilage cell maturation. Similarly, the increase in hypertrophic cartilage width resulted from a still more severe reduction in the rate of mineralization and resorption of the provisional cartilage. Endochondral ossification, including the formation of both primary and secondary spongiosa, was qualitatively normal in all rats in groups 1-3, but obviously rachitic in all rats in group 4 (Fig. 4).

\section{Discussion}

The three regimens used in this experiment would have produced different profiles of putatively active vitamin $\mathrm{D}$ metabolites. Rats given calcidiol are able to make $24,25(\mathrm{OH})_{2} \mathrm{D}_{3}$, $1,25(\mathrm{OH})_{2} \mathrm{D}_{3}$, and $1,24,25(\mathrm{OH})_{3} \mathrm{D}_{3}(2)$. Fluorine groups in position 24 function like hydrogen groups with respect both to receptor binding and biologic activity (17), but cannot be converted to hydroxyl groups $(15,16)$, so that rats given $24,24 \mathrm{~F}_{2} 25 \mathrm{OHD}_{3}$ will be exposed to analogues of both calcidiol and calcitriol but are unable to make $24,25(\mathrm{OH})_{2} \mathrm{D}_{3}$ or $1,24,25(\mathrm{OH})_{3} \mathrm{D}_{3}$. Finally, rats given calcitriol will be lacking in both $25 \mathrm{OHD}_{3}$ and $24,25 \mathrm{OH}_{2} \mathrm{D}_{3}$, but are able to make $1,24,25(\mathrm{OH})_{3} \mathrm{D}_{3}$. These relationships are summarized in Table VI, which demonstrates that each of the metabolites or analogues discussed, other than calcitriol, was missing in at least one of

Table III. Osteoid Indices and Cortical Porosity (Vascular Canal Area) in Different Experimental Groups

\begin{tabular}{|c|c|c|c|c|c|}
\hline $\begin{array}{l}\text { Group }(n) \\
\text { Treatment }\end{array}$ & $\begin{array}{l}1(10) \\
\text { Calcitriol }\end{array}$ & $\begin{array}{l}2(9) \\
24,24 F_{2}\end{array}$ & $\begin{array}{l}3(11) \\
\text { Calcidiol }\end{array}$ & $\begin{array}{l}\text { Pooled(30) } \\
\text { D-+ }\end{array}$ & $\begin{array}{l}4(12) \\
D--\end{array}$ \\
\hline \multicolumn{6}{|l|}{ Femur } \\
\hline Vascular canal (\% tissue) & $3.56 \pm 1.60 \S$ & $2.61 \pm 2.19 \S$ & $2.31 \pm 2.01 \S$ & $2.81 \pm 1.96 \S$ & $26.92 \pm 24.31$ \\
\hline Mineralized bone* (\% tissue) & $94.43 \pm 1.75 \S$ & $95.32 \pm 2.08 \S$ & $95.37 \pm 2.04 \S$ & $95.05 \pm 1.94 \S$ & $50.41 \pm 9.06$ \\
\hline Osteoid (\% tissue) & $2.02 \pm 0.33 \S$ & $2.07 \pm 0.35 \S$ & $2.31 \pm 0.46 \S$ & $2.12 \pm 0.40 \S$ & $22.67 \pm 9.76$ \\
\hline Osteoid (\% bone $\ddagger$ ) & $2.09 \pm 0.36 \S$ & $2.07 \pm 0.35 \S$ & $2.37 \pm 0.47 \S$ & $2.20 \pm 0.42 \S$ & $30.83 \pm 12.43$ \\
\hline Osteoid thickness $(\mu m)$ & $6.37 \pm 0.85 \S$ & $6.19 \pm 0.52 \S$ & $6.48 \pm 0.52 \S$ & $6.34 \pm 0.64 \S$ & $11.26 \pm 1.22$ \\
\hline \multicolumn{6}{|l|}{ Vertebra } \\
\hline Osteoid (\% bone) & $6.99 \pm 3.71 \S$ & $7.67 \pm 3.21 \S$ & $9.62 \pm 4.56 \S$ & $8.09 \pm 3.90 \S$ & $37.81 \pm 7.25$ \\
\hline Osteoid thickness $(\mu m)$ & $6.08 \pm 0.89 \S$ & $5.32 \pm 0.42 \S$ & $5.21 \pm 0.93 \S$ & $5.54 \pm 0.85 \S$ & $15.37 \pm 2.91$ \\
\hline
\end{tabular}

Data expressed as means \pm SD. One way analysis of variance showed no significant difference between groups 1,2 , and 3 for any measurement or derived index. $P$ values refer to comparisons with group 4; for the pooled group the smallest $t$ value was $>11$. * Determined by subtracting vascular canal and osteoid values from 100 . ₹ Total cortical area less vascular canal area. $\$ P<0.001$. 
Table IV. Appositional Rates and Bone Formation Rates Determined by Double Tetracycline Labeling in Different Experimental Groups

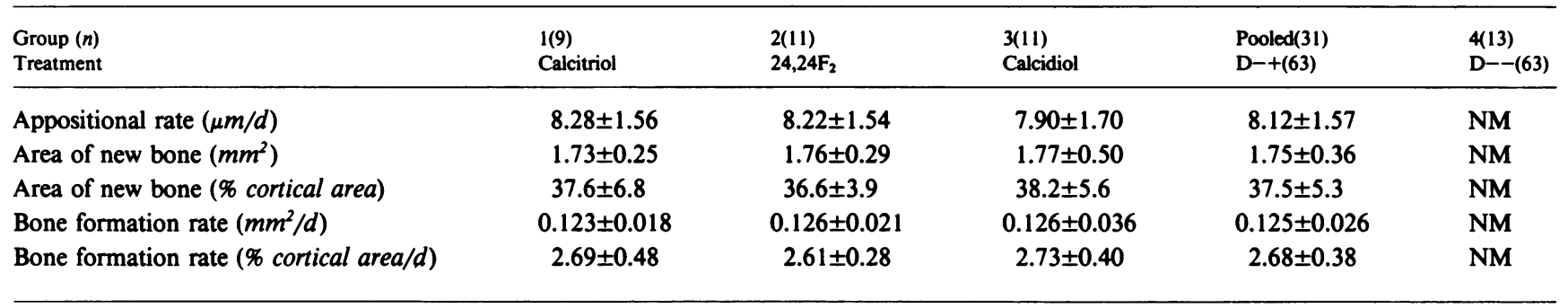

Data expressed as means \pm SD. NM, Not measurable. Other notes and symbols as in Table I. Bone formation rates obtained by dividing areas by $14 \mathrm{~d}$, the mean time interval between the labels. One-way analysis of variance showed no significant differences between groups 1,2 , and 3 .

the treated groups. The attainment of normal growth and development of bone in the absence of a compound demonstrates that the compound is not essential for these processes. We stress that lack of an essential function is not the same as lack of any biologic activity, and each of the compounds listed, when present, may have contributed to the observed histologic effects.

The three forms of vitamin $D$ we compared were equally effective in reversing all the morphologic consequences of vitamin D deficiency. In drawing this conclusion, we discount the minor differences in proliferative and hypertrophic cartilage width, for several reasons. First, they were of trivial magnitude. Second, their apparent statistical significance must be considered in relation to the number of variables compared; from the binomial theorem (28), with 16 separate comparisons there is almost a $15 \%$ chance that at least two would be significant at the $5 \%$ level with data derived from random numbers. Third, the differences made no physiologic sense. If $24,25 \mathrm{OH}_{2} \mathrm{D}_{3}$ is important, both groups 1 and 2 would have been significantly more abnormal than group 3, and if calcidiol was important in its own right then both groups 2 and 3 would have been significantly less abnormal than group 1 (Table VI). Thus, the data do not support either of these possibilities. The similarity of total epiphyseal cartilage width in all three groups was previously observed for $24,24 \mathrm{~F}_{2} 25 \mathrm{OHD}_{3}$ and calcidiol (19).

We infer an apparent need for 25-hydroxylation and lack of need for 24-hydroxylation for full biologic activity from the properties of the 24,24-difluoro compound. The validity of this inference must be reconciled with the earlier demonstration that

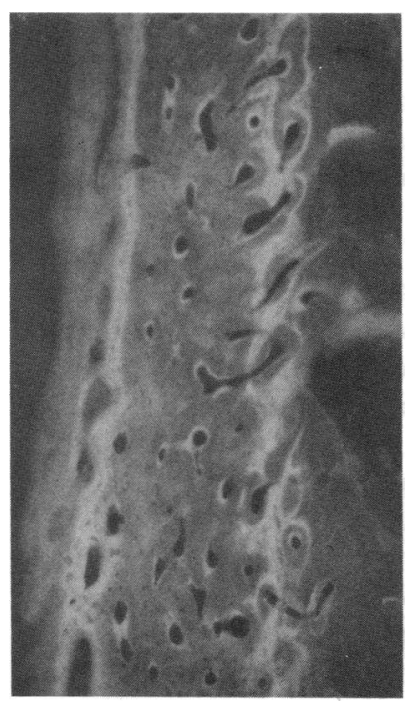

$1,25(\mathrm{OH})_{2} \mathrm{D}_{3}$

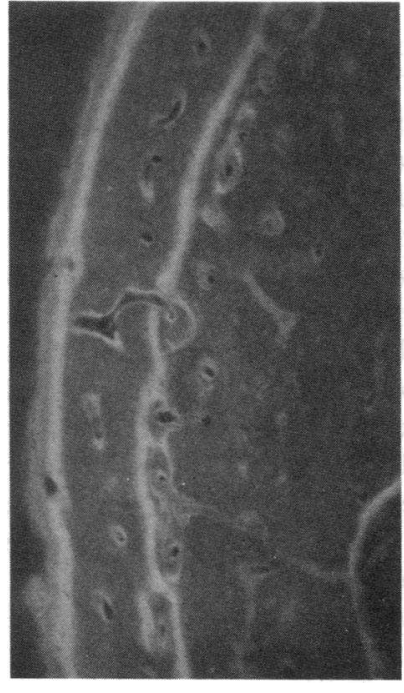

$24,24, \mathrm{~F}_{2} 25 \mathrm{OHD} \mathrm{D}_{3}$

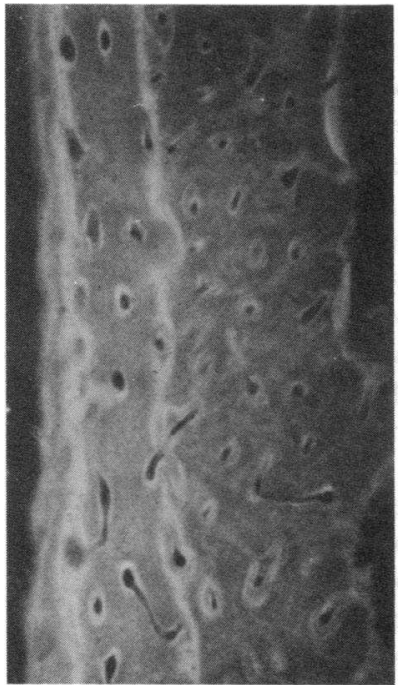

$25 \mathrm{OHD}_{3}$

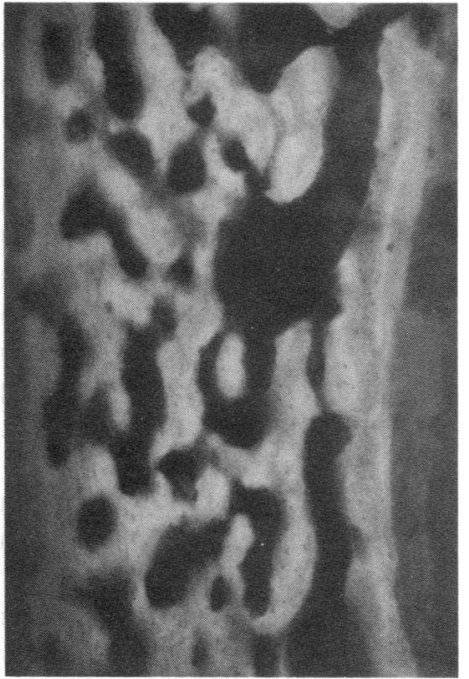

NO VITAMIN D

Figure 3. Representative segments of femoral diaphysis with UV illumination. Note paired periosteal (left side) fluorescent bands in groups 1, 2, and 3 , and diffuse fluorescence in group 4. 
Table V. Epiphyseal Growth Plate Cartilage Widths in Tail Vertebra in Different Experimental Groups

\begin{tabular}{|c|c|c|c|c|c|c|c|}
\hline $\begin{array}{l}\text { Group }(n) \\
\text { Treatment }\end{array}$ & $\begin{array}{l}1(10) \\
\text { Calcitriol }\end{array}$ & $\begin{array}{l}2(10) \\
24,24 F_{2}\end{array}$ & $\begin{array}{l}3(11) \\
\text { Calcidiol }\end{array}$ & $\begin{array}{l}\text { Pooled(31) } \\
\text { D-+(63) }\end{array}$ & $\begin{array}{l}4(12) \\
D--(65)\end{array}$ & $F$ & $P$ \\
\hline Proliferative cartilage width $(\mu m)$ & $65.2 \pm 9.5 \ddagger$ & $66.9 \pm 12.0 \ddagger$ & $79.0 \pm 13.1^{*}$ & $70.7 \pm 12.9 \ddagger$ & $99.8 \pm 17.8$ & 4.430 & $<0.05$ \\
\hline Hypertrophic cartilage width $(\mu m)$ & $59.5 \pm 5.0 \ddagger$ & $69.0 \pm 16.9 \ddagger$ & $55.2 \pm 9.4 \ddagger$ & $61.0 \pm 12.5 \ddagger$ & $151.7 \pm 33.7$ & 3.978 & $<0.05$ \\
\hline Total growth plate width $(\mu m)$ & $124.7 \pm 9.2 \ddagger$ & $135.9 \pm 20.00 \ddagger$ & $134.2 \pm 16.2 \ddagger$ & $131.7 \pm 16.0 \ddagger$ & $251.5 \pm 41.4$ & 1.458 & NS \\
\hline
\end{tabular}

Data expressed as mean \pm SD. Explanatory notes and symbols as in Table I. $P$ values refer to comparison with group $4, F$ values and corresponding $P$ values refer to one-way analysis of variance for groups 1,2 , and 3 .

24-OH-25-fluoro-vitamin $\mathrm{D}_{3}$, a compound that can be 1-hydroxylated but not 25 -hydroxylated, promotes intestinal absorption and bone release of calcium as effectively as $25-\mathrm{OH}-$ vitamin $\mathrm{D}_{3}(30,31)$. These studies demonstrated that there is no absolute requirement for 25 -hydroxylation, and that either a $25-\mathrm{OH}$ group or a $24-\mathrm{OH}$ group can confer biologic activity in conjunction with the 1-OH group. However, the presence of both $24-\mathrm{OH}$ and $25-\mathrm{OH}$ groups substantially reduces both receptor affinity and biologic activity (17). The ability of $1,24(\mathrm{OH})_{2} \mathrm{D}_{3}$, with or without a 25 -fluoro group, to mimic $1,25(\mathrm{OH})_{2} \mathrm{D}_{3}$, is relevant to the stereochemistry of receptorligand interaction but is of no physiologic importance, since the former compound is never produced in significant amounts in intact animals.

Thus, our data demonstrated that calcidiol, $24,25(\mathrm{OH})_{2} \mathrm{D}_{3}$, and $1,24,25(\mathrm{OH})_{3} \mathrm{D}_{3}$ were not necessary in the rat for longitudinal or transverse bone growth, including their relative rates needed for maintenance of bone shape; for the formation, maturation, mineralization, and resorption of epiphyseal growth plate cartilage and primary and secondary spongiosa in endochondral ossification; for periosteal and endosteal bone matrix formation and mineralization; for net endosteal resorption to accomplish marrow cavity expansion; and for maintenance of normal intracortical porosity by closure of primary osteons. The data previously reported about the same animals demonstrated a lack of need for these metabolites for attainment of normal body weight, normal plasma calcium levels and normal total, ash and organic weights of the femur (22). A similar lack of need for these metabolites is evident during the early administration of vitamin $\mathrm{D}$ to patients with vitamin $\mathrm{D}$ deficiency, in whom plasma calcitriol rises rapidly to above normal levels, plasma calcidiol remains low, and no $24,25 \mathrm{OH}_{2} \mathrm{D}_{3}$ is formed for several weeks $(32,33)$.

Calcitriol was fully active with respect to each of the bone cellular functions and indices previously listed, when given in a manner that closely resembles its continuous endogenous production by the kidney, thereby ensuring that its plasma level remained within the physiologic range at all times. By contrast, when calcitriol is given by intermittent oral or intraperitoneal administration $(4,5,10,14)$, because of its rapid clearance, the plasma level must oscillate between high and low levels. In this circumstance a normal physiologic response is hardly to be expected, although elevation of plasma phosphate due to in- creased renal tubular reabsorption may be more dependent on a sustained and stable plasma calcitriol level than elevation of plasma calcium due to increased intestinal absorption (14). Only in one study have at least normal plasma calcitriol levels been continuously maintained between doses (5), but the peak levels exceeded $2,000 \mathrm{pg} / \mathrm{ml}$ (10-20 times normal) and growth was retarded, so that the incomplete histologic response in bone most likely resulted from a toxic effect on bone cells. In some patients with vitamin $\mathrm{D}$ deficiency who are given calcitriol once daily by mouth, the plasma phosphate rises and osteomalacia heals (34), especially if the plasma calcitriol level is adequately maintained between doses (35), but in other patients neither a rise in plasma phosphate nor healing of osteomalacia are achieved $(3,36)$; these different responses could reflect individual differences in the rate of catabolism of calcitriol.

Inability of calcitriol to carry out all the functions of vitamin $\mathrm{D}$ has also been inferred from discrepancies between the plasma concentrations of various metabolites and the histologic changes in bone in patients $(6,12,35-39)$ or in experimental animals $(11,40)$ receiving only vitamin $D$. In this circumstance any calcitriol present is of endogenous origin from the kidney, so that its short half life would not impair its biologic effectiveness. There have been several reports of patients with adequate histologic documentation of osteomalacia due to vitamin D deficiency in whom plasma calcitriol levels have fallen within the range found in healthy subjects $(35-37,41)$, and in patients with intestinal malabsorption of vitamin $D$, even above that range (6). It is misleading to characterize these patients' calcitriol levels as normal, since this level varies widely according to the physiologic state of the organism $(1,2)$; the reported values are lower than would be expected for the degree of secondary hyperparathyroidism (42), and are much lower than the supraphysiologic levels observed in the early stages of vitamin D repletion in patients with osteomalacia $(32,33)$.

But it is also appropriate to relate the plasma level of calcitriol to the effects of this hormone on its target cells. From this standpoint, the presence of calcium malabsorption without calcitriol deficiency in patients without primary intestinal disease requires explanation, in the sense that the intestinal mucosal cells appear to be responding to some additional signal. In these and other patients, both the biochemical and bone histologic state appear to correlate best with the sum of calcidiol and calcitriol levels in plasma $(41,43)$. Calcidiol might function as 

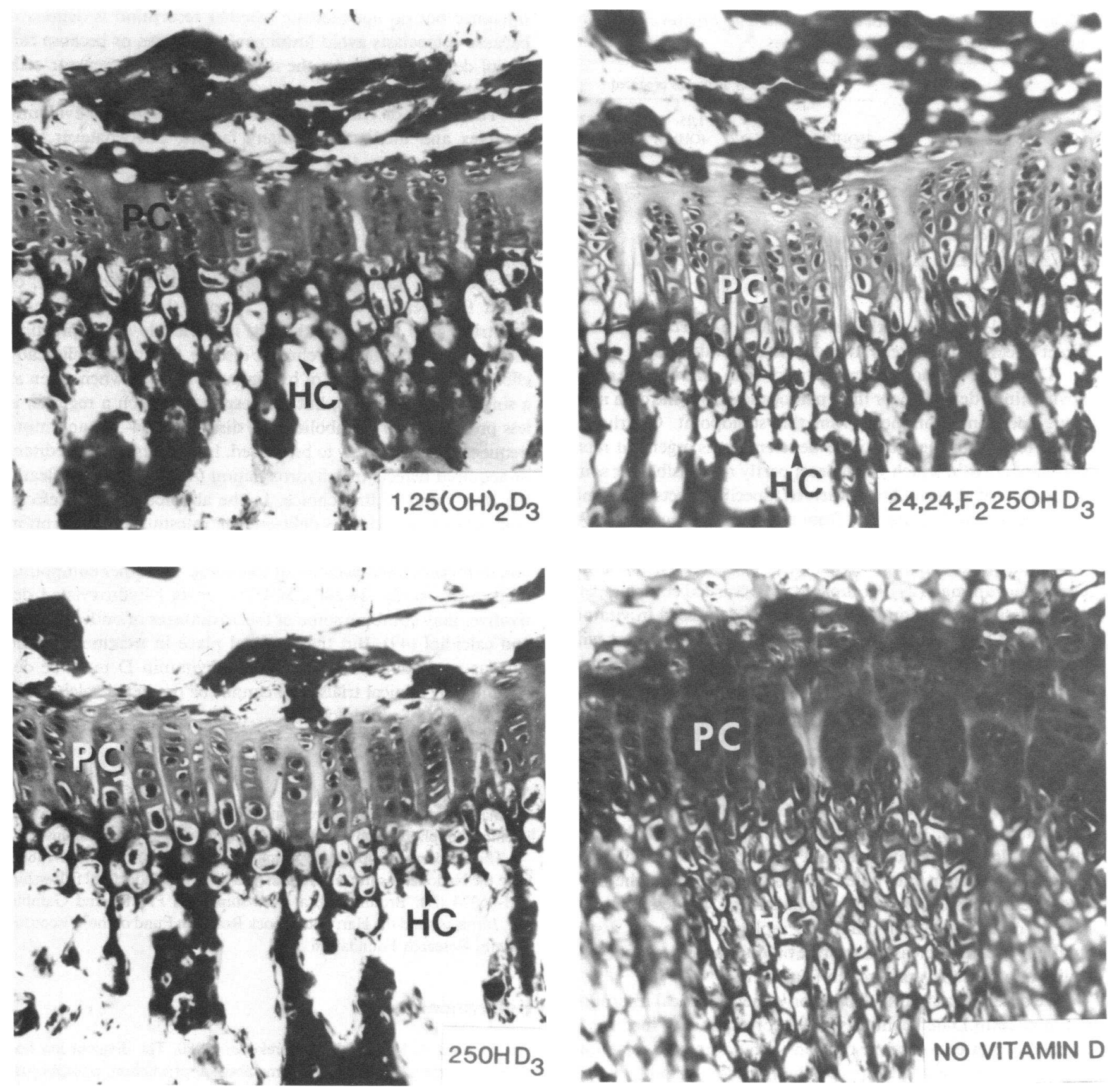

Figure 4. Representative longitudinal sections of vertebral growth plates. Layout as in Fig. 1. PC, proliferative cartilage; $H C$, hypertrophic cartilage. Note increased growth plate width in untreated group.

an agonist for calcitriol, its higher concentration compensating for its lower receptor affinity (1). Alternatively, calcidiol might function in a permissive manner, such that when the plasma calcidiol falls below some critical level, more calcitriol is needed to produce the same effects (44). Our own data do not necessarily rule out this concept, since the daily production rate of calcitriol in groups 2 and 3 was not measured and might have been smaller than the dose infused in group 1. Such explanations for discordance between bone histology and plasma calcitriol levels do not assign an essential role to calcidiol except as a precursor 
Table VI. Vitamin D Metabolite or Analogue Profiles Produced by the Different Experimental Regimens

\begin{tabular}{llllll}
\hline & & \multicolumn{4}{c}{ Metabolites or analogues produced } \\
\cline { 3 - 6 } Group & $\begin{array}{l}\text { Compound } \\
\text { administered }\end{array}$ & $2^{25 O H D_{3}}$ & $\begin{array}{l}24,25- \\
(\mathrm{OH})_{2} \mathrm{D}_{3}\end{array}$ & $\begin{array}{l}1,25- \\
(\mathrm{OH})_{2} \mathrm{D}_{3}\end{array}$ & $\begin{array}{l}1,24,25- \\
(\mathrm{OH})_{3} \mathrm{D}_{3}\end{array}$ \\
\hline 1 & Calcitriol & - & - & + & + \\
2 & $24,24, \mathrm{~F}_{2} 25 \mathrm{OHD}$ & + & - & + & - \\
3 & Calcidiol & + & + & + & + \\
4 & Vehicle only & - & - & - & - \\
\hline
\end{tabular}

to calcitriol, or require that any vitamin D metabolite has a direct effect on bone cells to promote mineralization.

This study was not designed primarily to examine the effects of vitamin $\mathrm{D}$ deficiency or their pathogenesis, but the data merit some additional comment from this standpoint. Clearly one major feature of the vitamin D-deficient rat is a general retardation of growth, which was at least partly responsible for some of the skeletal abnormalities observed. Specific effects of vitamin D deficiency can be separated from nonspecific effects of growth retardation by pair feeding of vitamin D-repleted animals to reduce their growth rate to the same extent as the vitamin D-deficient animals (29). Compared with pair-fed controls, periosteal matrix apposition was significantly depressed in vitamin D-deficient rats (29), an abnormality that correlated best with hypocalcemia and that can be corrected by calcium administration without vitamin D (45). Pair feeding was not used in the present study, so that the relative contributions of hypocalcemia and general growth retardation to the reduction in periosteal bone formation cannot be determined, although most likely both were important. In the vitamin D-deficient rats, longitudinal growth of the femur was much more retarded than transverse growth, with a significant fall in the length/width ratio (Table $\mathrm{I}$ ). This ratio was not significantly affected in the vitamin D-deficient rats killed at weaning, in whom the morphologic expression of vitamin D deficiency was less apparent than in older rats. With vitamin D repletion there was a substantially greater increase in the rate of longitudinal growth than in the rate of transverse growth (Table II).

We observed a striking depression of net endosteal resorption in the vitamin D-deficient rats and a corresponding increase in the rate of net endosteal resorption with vitamin $D$ repletion, which was intermediate between the increases in rates of longitudinal and of transverse growth (Table II). Consequently, depressed endosteal resorption rather than preservation of periosteal matrix production was responsible for the relatively smaller reduction in femoral organic weight than in body weight in the vitamin D-deficient rats (22). Resorption of primary spongiosa was also severely depressed. In pair-fed vitamin D-deficient rats, endosteal resorption was increased, most likely because of secondary hyperparathyroidism, but to a lesser extent than expected, and a primary effect of vitamin $D$ deficiency to reduce bone resorption was therefore inferred $(29,45)$. Our data support this inference but do not indicate whether resorption is depressed because osteoclasts avoid unmineralized tissue, or because calcitriol deficiency impairs the differentiation of precursor cells into osteoclasts (46).

The effects of vitamin $\mathrm{D}$ deficiency on bone are evidently complex and mediated by many factors, but whatever their relative importance, they were all equally well corrected by the three metabolites used in the present study and all data, both from laboratory animals and from patients, support the conclusion that calcitriol can accomplish all the functions of vitamin D. We emphasize again that this is a conclusion about physiology, not about the pathogenesis of disease, as discussed earlier, or about therapeutics. Continuous parenteral administration of calcitriol, as is needed in the rat, is obviously not a practical form of treatment for any chronic disease. Calcitriol is clinically effective in various types of hypoparathyroidism when given as a single daily dose (47), but the response to such a regimen is less predictable in metabolic bone disease $(3,34-36)$ and more frequent doses are likely to be needed. In patients with hereditary or acquired defects in 1-hydroxylation (48), calcitriol is clearly the compound of first choice. In the absence of such defects, as in patients with dietary deficiency or intestinal malabsorption of vitamin $\mathrm{D}$, an alternative method of supplying calcitriol is to administer either calcidiol or calciferol. The other compound used in this study, $24,24 \mathrm{~F}_{2} 25 \mathrm{OHD}_{3}$, or its 1-hydroxylated derivative, may combine some of the advantages of both calcitriol and calcidiol (49). But the eventual place in treatment of the various metabolites and analogues of vitamin $D$ must be determined by clinical trials, and cannot be predicted solely from a knowledge of physiology.

\section{Acknowledgments}

We thank Mary Kujawa for preparation of the histologic sections, Wayne Pitchford for photography, and Jessie Miller for preparing the manuscript.

This work was supported by Program Project grant No. AM-14881 from the National Institutes of Health (NIH), NIH postdoctoral fellowship AM-06374 (Dr. Brommage), a fellowship from Procter and Gamble (Dr. Jarnagin) and the Harry Steenbock Research Fund of the Wisconsin Alumni Research Foundation.

\section{References}

1. Parfitt, A. M., and M. Kleerekoper. 1980. The divalent ion homeostatic system. Physiology and metabolism of calcium, phosphorus, magnesium and bone. In Clinical Disorders of Fluid and Electrolyte Metabolism. M. Maxwell and C. R. Kleeman, editors. Third ed. 269398.

2. DeLuca, H. F. 1981. Recent advances in the metabolism of vitamin D. Ann. Rev. Physiol. 43:199-209.

3. Bordier, P., H. Rasmussen, P. Marie, L. Miravet, J. Gueris, and A. Ryckewaert. 1978. Vitamin D metabolites and bone mineralization in man. J. Clin. Endocrinol. Metab. 46:284-294.

4. Queille, M. L., L. Miravet, P. Bordier, and J. Redel. 1978. The action of vitamin $\mathrm{D}$ metabolites $\left(25 \mathrm{OHD}_{3}-1,25(\mathrm{OH})_{2} \mathrm{D}_{3}-25,26(\mathrm{OH})_{2} \mathrm{D}_{3}\right)$ on vitamin $\mathrm{D}$ deficient rats. Biomedicine. 28:237-242. 
5. Gallagher, J. A., and D. E. M. Lawson. 1980. Histological observations on the failure of rachitic rat bones to respond to $1,25(\mathrm{OH})_{2} \mathrm{D}_{3}$. Calcif. Tissue Int. 31:215-223.

6. Rasmussen, H., R. Baron, A. Broadus, R. DeFronzo, R. Lang, and $R$. Horst. 1980. $1,25-(\mathrm{OH})_{2} \mathrm{D}_{3}$ is not the only $\mathrm{D}$ metabolite involved in the pathogenesis of osteomalacia. Am. J. Med. 69:360-368.

7. Corvol, M. T., M. F. Dumontier, M. Garabedian, and R. Rappaport. 1978. Vitamin D and cartilage. II. Biological activity of 25hydroxy-cholecalciferol and 24,25- and 1,25-dihydroxycholecalciferol on cultured growth plate chondrocytes. Endocrinology. 102:1269-1274.

8. Ornoy, A., D. Goodwin, D. Noff, and S. Edelstein. 1978. 24,25Dihydroxyvitamin D is a metabolite of vitamin D essential for bone formation. Nature (Lond.). 276:517-519.

9. Galus, K., J. Szymendera, A. Zaleski, and K. Schrever. 1980. Effects of 1-hydroxyvitamin $D_{3}$ and 24R,25-dihydroxyvitamin $D_{3}$ in bone remodeling. Calcif. Tissue Int. 31:209-213.

10. Malluche, H. H., H. Henry, W. Meyer-Sabellek, D. Sherman, S. G. Massry, and A. W. Norman. 1980. Effects and interactions of 24R,25- $(\mathrm{OH})_{2} \mathrm{D}_{3}$ and 1,25- $(\mathrm{OH})_{2} \mathrm{D}_{3}$ on bone. Am. J. Physiol. 238:E494E498.

11. Norman, A. W., J. Roth, and L. Orci. 1982. The vitamin D endocrine system: steroid metabolism, hormone receptors, and biological response (calcium binding proteins). Endocrine Rev. 3:331-366.

12. Kanis, J. A., D. Guilland-Cumming, A. D. Paterson, and R. G. G. Russell. 1982. The role of $1,25(\mathrm{OH})_{2} \mathrm{D}_{3}$ and $24,25(\mathrm{OH})_{2} \mathrm{D}_{3}$ in calcium homeostasis. In Vitamin D, Chemical, Biochemical and Clinical Endocrinology of Calcium Metabolism. A. W. Norman, K. Schaefer, D. V. Herrath and H.-G. Grigoleit, editors. Walter de Gruyter, New York. 157-167.

13. Ott, S. M., J. W. Coburn, N. A. Maloney, A. C. Alfrey, and D. J. Sherrard. 1982. Bone aluminum and response to vitamin D metabolites in renal osteodystrophy. In Vitamin D, Chemical, Biochemical and Clinical Endocrinology of Calcium Metabolism. A. W. Norman, K. Schaefer, D. v. Herrath, and H.-G. Grigoleit, editors. Walter de Gruyter, New York. 869-871.

14. Tanaka, Y., and H. F. DeLuca. 1974. Role of 1,25-dihydroxyvitamin $\mathrm{D}_{3}$ in maintaining serum phosphorus and curing rickets. Proc. Natl. Acad. Sci. USA. 71:1040-1044.

15. Tanaka, Y., H. F. DeLuca, Y. Kobayashi, T. Taguchi, N. Ikekawa, and M. Morisaki. 1979. Biological activity of 24,24-difluoro-25-hydroxyvitamin $D_{3}$. Effect of blocking of 24-hydroxylation on the functions of vitamin D. J. Biol. Chem. 254:7163-7167.

16. Halloran, B. P., H. F. DeLuca, E. Barthell, S. Yamada, M. Ohmori, and H. Takayama. 1981. An examination of the importance of 24-hydroxylation to the function of vitamin D during early development. Endocrinology. 108:2067-2071.

17. Tanaka, Y., J. K. Wichman, H. F. DeLuca, Y. Kobayashi, and N. Ikekawa. 1983. Metabolism and binding properties of 24,24-difluoro25-hydroxyvitamin $\mathrm{D}_{3}$. Arch. Biochem. Biophys. 225:649-655.

18. Okamoto, S., Y. Tanaka, H. F. DeLuca, S. Yamada, and H. Takayama. 1981. 24,24-Difluoro-25-hydroxyvitamin $\mathrm{D}_{3}$-enhanced bone mineralization in rats. Comparison with 25 -hydroxyvitamin $D_{3}$ and vitamin $\mathrm{D}_{3}$. Arch. Biochem. Biophys. 206:8-14.

19. Miller, S. C., B. P. Halloran, H. F. DeLuca, S. Yamada, H. Takayama, and W. S. S. Jee. 1981. Studies on the role of 24-hydroxylation of vitamin D in the mineralization of cartilage and bone of vitamin D-deficient rats. Calcif. Tissue Int. 33:489-497.

20. Suda, T., H. F. DeLuca, and Y. Tanaka. 1970. Biological activity of 25-hydroxycholecalciferol in rats. J. Nutr. 100:1049-1052.

21. Jarnagin, K., R. Brommage, H. F. DeLuca, S. Yamada, and H.
Takayama. 1983. 1- but not 24-hydroxylation of vitamin D is required for growth and reproduction in rats. Am. J. Physiol. 244:E290-E297.

22. Brommage R., K. Jarnagin, H. F. DeLuca, S. Yamada, and H. Takayama. 1983. 1- but not 24-hydroxylation of vitamin $D_{3}$ is required for normal skeletal mineralization in rats. Am. J. Physiol. 244:E298E304.

23. Villanueva, A. R. 1976. Method of preparing and interpreting mineralized sections of bone. In Proceedings of the First International Workshop on Bone Morphometry. Z. F. G. Jaworski, editor. University of Ottawa Press, Ottawa. 341-353.

24. Mathews, C. H. E., and L. Mehr. 1979. Staining and processing bone specimens for simultaneous tetracycline-osteoid seam assessment and histomorphometric quantitative analysis. J. Histotechnol. 2:23-24.

25. Villanueva, A. R., G. Czupinski, and A. M. Parfitt. 1979. A toluidine blue stain for calcification front, cement line and osteoid seams in plastic embedded undecalcified sections of bone. J. Histotechnol. 2:139.

26. Malluche, H. M., D. Sherman, W. Meyer, and S. G. Massry. 1982. A new semiautomatic method for quantitative static and dynamic bone histology. Calcif. Tissue Int. 34:430-448.

27. Parfitt, A. M. 1983. The stereologic basis of bone histomorphometry. Theory of quantitative microscopy and reconstruction of the 3rd dimension. In Bone Histomorphometry. Techniques and Interpretations. R. Recker, editor. CRC Press, Boca Raton, FL.

28. Hayslett, H. T. 1967. Statistics Made Simple. Doubleday \& Co., Inc., New York.

29. Baylink, D., M. Stauffer, J. Wergedal, and C. Rich. 1970. Formation, mineralization, and resorption of bone in vitamin D-deficient rats. J. Clin. Invest. 49:1122-1134.

30. Napoli, J. L., W. S. Mellon, M. A. Fivizzani, H. K. Schnoes, and H. F. DeLuca. 1978. Synthesis and biological activity of 24-hydroxy25-fluorovitamin $\mathrm{D}_{3}$. A highly potent mediator of calcium metabolism. Biochemistry. 17:23972392.

31. Napoli, J. L., W. S. Mellon, H. K. Schnoes, and H. F. DeLuca. 1979. Evidence for the metabolism of 24R-hydroxy-25-fluorovitamin $\mathrm{D}_{3}$ and la,24R-dihydroxy-25-fluorovitamin $\mathrm{D}_{3}$. Arch. Biochem. Biophys. 197:193-198.

32. Papapoulos, S. E., T. L. Clemens, L. J. Fraher, J. Gleed, and J. L. H. O'Riordan. 1980. Metabolites of vitamin $D$ in human vitamin$D$ deficiency: Effect of vitamin $D_{3}$ or 1,25-dihydroxycholecalciferol Lancet. II:612-615.

33. Stanbury, S. W., C. M. Taylor, G. A. Lumb, E. B. Mawer, J. Berry, J. Hann, and J. Wallace. 1981. Formation of vitamin D metabolites following correction of human vitamin D deficiency. Observations in patients with nutritional osteomalacia. Miner. Electrolyte Metab. 5:212227.

34. Nagant de Deuxchaisnes, C., C. Rombouts-Lindemans, J. P. Huaux, H. Withofs, and F. Meersseman. 1979. Healing of vitamin D-deficient osteomalacia by the administration of $1,25-(\mathrm{OH})_{2} \mathrm{D}_{3}$. In Molecular Endocrinology. I. MacIntyre and M. Szelke, editors. ElsevierNorth Holland Biomedical Press, Amsterdam. 375-404.

35. Peacock, M., P. J. Heyburn, J. E. Aaron, G. A. Taylor, W. B. Brown, and R. Speed. 1979. Osteomalacia: treated with 1 hydroxy or 1,25 dihydroxy vitamin D. In Vitamin D. Basic Research and its Clinical Application. A. W. Norman, K. Schaefer, D. v. Herrath, H.-G. Grigoleit, J. W. Coburn, H. F. DeLuca, E. B. Mawer, and T. Suda, editors. Walter de Gruyter, Berlin. 1177-1183.

36. Rasmussen, H., and P. Bordier. 1978. Vitamin D and bone. Metab. Bone Dis. Rel. Res. 1:7-13.

37. Eastwood, J. B., H. E. de Wardener, R. W. Gray, and J. L. 
Lemann, Jr. 1979. Normal plasma 1,25-(OH) - -Vitamin D concentrations in nutritional osteomalacia. Lancet. I:1377-1378.

38. Kashiwa, H., Y. Nishi, T. Usui, and Y. Seino. 1981. A case of rickets with normal serum level of $1,25-(\mathrm{OH})_{2} \mathrm{D}$ and low 25-OHD. $\mathrm{Hi}$ roshima J. Med. Sci. 30:61-63.

39. Bordier, Ph. J., S. Tun Chot, J. T. Eastwood, A. Fournier and H. E. de Wardener. 1973. Lack of histological evidence of vitamin D abnormality in the bones of anephric patients. Clin. Sci. (Lond.). 44:33-41.

40. Harrison, J. E., A. J. W. Hitchman, G. Jones, C. S. Tam, and J. N. M. Heersche. 1982. Plasma vitamin D metabolite levels in phosphorus deficient rats during the development of vitamin D deficient rickets. Metab. Clin. Exp. 31:1121-1127.

41. Rao, D. S., A. Villanueva, M. Mathews, B. Pumo, B. Frame, and A. M. Parfitt. 1983. Histologic evolution of vitamin-D depletion in patients with intestinal malabsorption or dietary deficiency. In Clinical Disorders of Bone and Mineral Metabolism. B. Frame and J. T. Potts, Jr., editors. Elsevier, Amsterdam. 224-226.

42. Chesney, R. W., J. Zimmerman, A. Hamstra, H. F. DeLuca, and R. B. Mazess. 1981. Vitamin D metabolite concentrations in vitamin D deficiency. Are calcitriol levels normal? Am. J. Dis. Child. 135:10251028.
43. Nordin, B. E. C., P. J. Heyburn, M. Peacock, A. Horsman, J. Aaron, D. Marshall, and R. G. Crilly. 1980. Osteoporosis and Osteomalacia. Clin. Endocrinol. Metab. 9:177-205.

44. Baylink, D. J., E. R. Morey, J. L. Ivey, and M. E. Stauffer. 1980. Vitamin D and bone. In Vitamin D: Molecular Biology and Clinical Nutrition. A. W. Norman, editor. Marcel Dekker, Inc., New York. 387 453.

45. Howard, G. A., and D. J. Baylink. 1980. Matrix formation and osteoid maturation in vitamin D-deficient rats made normocalcemic by dietary means. Miner. Electrolyte Metab. 3:44-50.

46. Bar-Shavit, Z., S. L. Teitelbaum, P. Reitsma, J. Trial, and A. J. Kahn. 1983. Induction of monocytic differentiation and bone resorption by 1,25-dihydroxyvitamin $\mathrm{D}_{3}$. Calcif. Tissue Int. 35:637. (Abstr.).

47. Markowitz, M. E., J. F. Rosen, C. Smith, and H. F. DeLuca. 1982. 1,25-dihydroxyvitamin D3-treated hypoparathyroidism: 35 patient years in 10 children. J. Clin. Endocrinol. Metab. 55:727-733.

48. Parfitt, A. M., and M. Kleerekoper. 1980. Clinical disorders of phosphorus and magnesium metabolism. In Clinical Disorders of Fluid and Electrolyte Metabolism. M. Maxwell and C. R. Kleeman, editors. Third ed. 947-1152.

49. DeLuca, H. F. 1980. Vitamin D: Revisited 1980. Clin. Endocrinol. Metab. 9:3-26. 